\title{
Guidelines should bother us, not comfort us
}

\author{
William M. DeCampli, MD, PhD
}

\footnotetext{
From the Department of Clinical Sciences, The University of Central Florida, Orlando, Fla; and Congenital Heart Surgeons Society Data Center, The Hospital for Sick Children, Toronto, Ontario, Canada.

Disclosures: Author has nothing to disclose with regard to commercial support.

Received for publication Sept 9, 2016; accepted for publication Sept 9, 2016; available ahead of print Oct 7, 2016. Address for reprints: William M. DeCampli, MD, PhD, The Heart Center, Arnold Palmer Hospital for Children, 80 W Miller St, Orlando, FL 32813 (E-mail: William.decampli@ucf.edu).

J Thorac Cardiovasc Surg 2017;153:1458-61

$0022-5223 / \$ 36.00$

Copyright (c) 2016 by The American Association for Thoracic Surgery

http://dx.doi.org/10.1016/j.jtcvs.2016.09.008
}

Anomalous aortic origin of a coronary artery (AAOCA) specifically one that takes an interarterial course-is an infrequent anomaly (prevalence, $0.2 \%-0.8 \%$ ) that is associated with a small incidence of sudden cardiac death, especially in athletes. The combination of high public visibility, low prevalence of the anomaly, and apparent low incidence of death caused by it, has been a cause célèbre for many publications promoting diagnostic algorithms and management schemes.

In this issue, Brothers and colleagues ${ }^{2}$ report findings and recommendations of The American Association for Thoracic Surgery-sanctioned AAOCA Guidelines Writing Committee on the diagnosis and management of this disorder. This review was sorely needed, and the authors have done a laudable job executing it. Additionally, this cyclopean effort has the collateral advantage of stimulating more thought and debate on this challenging anomaly. For example, consider the following:

The authors make a Class I, Level B recommendation for surgical treatment for any operative patient with anomalous

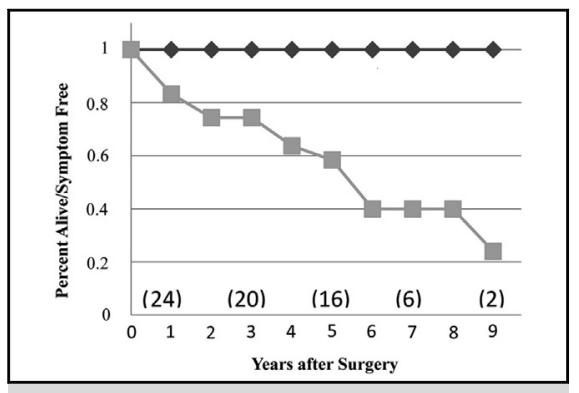

Freedom from cardiac symptoms after anomalous aortic origin of a coronary artery repair. Reprinted with permission.

\section{Central Message}

The new guidelines for management of anomalous aortic origin of a coronary artery may be the best we have, but the evidence base should still concern us.

See Article page 1440.

TABLE 1. Tabulated statistics from 11 recent case series publications and a review of 50 case reports (1-3 cases each report)

\begin{tabular}{|c|c|c|c|c|c|c|c|}
\hline Publication & $\begin{array}{c}\text { No. of cases } \\
\text { operated for } \\
\text { AAOLCA }\end{array}$ & $\begin{array}{c}\text { Mean follow-up, } \\
\text { y (range) }\end{array}$ & $\begin{array}{c}\text { Postoperative } \\
\text { deaths }\end{array}$ & $\begin{array}{l}\text { Preoperative } \\
\text { symptoms }\end{array}$ & $\begin{array}{c}\text { Preoperative } \\
\text { positive } \\
\text { provocative test }\end{array}$ & $\begin{array}{c}\text { Postoperative } \\
\text { symptoms }\end{array}$ & $\begin{array}{c}\text { Postoperative } \\
\text { positive test }\end{array}$ \\
\hline Romp $2003^{3}$ & 6 & $2.5(0.3-7)$ & $0 / 6$ & $6 / 6$ & $1 / 2$ & $0 / 6$ & $0-1 / 6$ \\
\hline Erez $2006^{4}$ & 4 & $1(0.3-2.5)$ & $0 / 4$ & $4 / 4$ & $0 / 4$ & $0 / 4$ & $0 / 4$ \\
\hline Osaki $2008^{5}$ & 7 & $2(1.2-3)$ & $0 / 7$ & $6 / 7$ & $4 / 5$ & $1 / 6$ & NA \\
\hline Levin $2010^{6}$ & 16 & NA & $0 / 16$ & $16 / 16$ & NA & NA & NA \\
\hline Turner $2011^{7}$ & 13 & 2.5 (NA) & $0 / 13$ & $6 / 13$ & NA & NA & NA \\
\hline Mumtaz $2011^{8}$ & 7 & 1.5 (median) $(0.1-5.2)$ & $0 / 7$ & $6 / 7$ & NA & $0 / 7$ & NA \\
\hline Frommelt $2011^{9}$ & 7 & $1.8(0.1-8)$ & $0 / 7$ & $4 / 7$ & $0 / 4$ & $0 / 7$ & NA \\
\hline Sharma $2014^{10}$ & 6 & $1.6(1-7)$ & $0 / 6$ & NA & NA & $0 / 6$ & $0 / 6$ \\
\hline $\begin{array}{l}\text { Wittlieb-Weber } 2014^{1} \\
\text { with Davis } 2007^{11}\end{array}$ & 8 & $4(1-9)$ & $0 / 8$ & $6 / 8$ & 2/NA & $5 / 8$ & $3 / 8(1 / 8$ ischemic $)$ \\
\hline Feins $2016^{12}$ & 6 & 3.8 (NA) & $0 / 6$ & $4-6 / 6$ & NA & $3 / 6$ & $1 / 4$ \\
\hline Mainwaring $2016^{13}$ & 37 & $6(0.2-16)$ & $0 / 37$ & $27 / 37$ & NA & $0 / 27$ & NA \\
\hline $\begin{array}{l}\text { Case reports (from } \\
\text { Nguyen } 2012^{14} \text { ) }\end{array}$ & 59 & $1.5(0.01-9)$ & $0 / 57$ & $52 / 52$ & NA & $3 / 46$ & NA \\
\hline
\end{tabular}




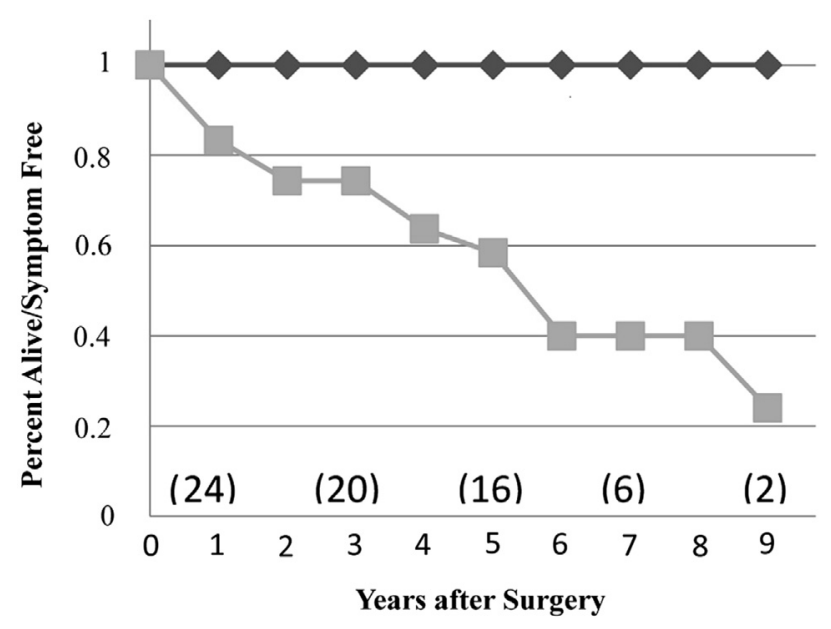

FIGURE 1. Freedom from cardiac symptoms after anomalous aortic origin of a coronary artery repair. Reprinted with permission. ${ }^{1}$

The total number of reported cases is 176 . The average of the mean durations of follow-up is about 2.6 years. There were no deaths. Seems like perfect results, but how do they compare with the natural history of untreated AAOLCA? Brothers and colleagues ${ }^{15}$ estimated that the cumulative risk of death over a 20 -year period was about $6.3 \%$ for AAOLCA patients participating in competitive sports. Taking this percentage as an upper limit (because most patients do not participate in competitive sports), one would expect 1 to 2 deaths during the average 2.6-year follow-up among the 176 patients in this collection of studies. At least on the basis of this comparison, with such short-term average follow-up, there does not seem to be strong evidence for the superiority of surgical versus not-surgical treatment.

Now consider, in this same set of 176 patients, the evidence that surgical operation relieves cardiac ischemia in AAOCLA. To test this, one must know how many patients had evidence of preoperative ischemia. As shown in Table 1, the evidence of preoperative ischemia is scant-most studies did not quantitatively evaluate it. This leaves symptoms as the only evidence of ischemiathe reliability of which (except for sudden cardiac collapse) is among the most hotly debated questions in those studying this disorder. Furthermore, the quantitative evaluation of postoperative ischemia is also scant, with the largest single study (Mainwaring and colleagues ${ }^{13}$ ) not reporting postoperative testing at all. Thus, whether surgery on AAOLCA results in a lower incidence of persistent or new quantitative evidence of ischemia still awaits better evidence, notwithstanding the intriguing results shown in Figure 1.

Figure 2 reproduces an August 2015 refinement of the American College of Cardiology/American Heart Association Clinical Practice Guidelines grading system, more granular than that used in the present article. ${ }^{16}$ Do we have objective evidence to strongly recommend surgery under all circumstances for AAOLCA (Class I), given that the margin in the above ad hoc comparative analysis of all of the Table 1 reports was only 1 or 2 deaths? Do we have 1 or more well-designed, well-executed studies with moderate quality evidence (Level B-NR), when we only have case reports or case studies subject to publication bias, when we average a few years' follow-up, and when we infrequently report quantitative ischemic tests for AAOLCA? We might consider being more humble so that we know we still have a problem here.

Perhaps it is time, as many have suggested, to focus on anatomic and clinical risk stratification of both AAOLCA and anomalous aortic origin of a right coronary artery, as well as accumulate greater length of follow-up. The Congenital Heart Surgeons' Society AAOCA registry, initiated in 2009, containing almost 600 patients and with 70 to 80 new enrollments per year, may provide the best opportunity to reach the next class of recommendation and level of evidence, because the cohort is to be followed for a lifetime. Studies based on the registry must be carefully crafted to provide prospective, serial, pre-, and postoperative quantitative evaluation of these patients by all Congenital Heart Surgeons' Society member institutions. How that is executed is still an organizational and regulatory challenge, but will be worth it. In the meantime, the current guidelines for surgical management of AAOCA, driven by the treatable anatomic nature of the anomaly and the Housmanian tragedy of sudden death in the young, ${ }^{17}$ represent an important update of our knowledge base and expert opinion. The status of our evidence base should continue to bother us.

\section{References}

1. Wittlieb-Weber C, Paridon S, Gaynor W, Spray T, Weber D, Brothers J. Medium-term outcome after anomalous aortic origin of a coronary artery repair in a pediatric cohort. J Thorac Cardiovasc Surg. 2014;147:1580-6.

2. Brothers JA, Frommelt MA, Jaquiss RDB, Myerbury RJ, Fraser CD, Tweddell JS. Expert consensus guidelines: Anomalous aortic origin of a coronary artery. J Thorac Cardiovasc Surg. 2017;153:1440-57.

3. Romp RL, Herlong R, Landolfo C, Sanders S, Miller C, Ungerleider R, et al Outcome of unroofing procedure for repair of anomalous aortic origin of left or right coronary artery. Ann Thorac Surg. 2003;76:589-96.

4. Erez E, Tam V, Doublin N, Stakes J. Anomalous coronary artery with aortic origin and course between the great arteries: improved diagnosis, anatomic findings, and surgical treatment. Ann Thorac Surg. 2006;82:973-7.

5. Osaki M, McCrindle B, Van Arsdell G, Dipchand A. Anomalous origin of a coronary artery from the opposite sinus of Valsalva with an interarterial course: clinical profile and approach to management in the pediatric population. Pediatr Cardiol. 2008;29:24-30.

6. Levin R, Degrange M, Lezana F, Sobre M, Salvaggio F, Blanco N, et al. Diagnosis and surgical treatment of the anomalous origin of the coronary arteries. Rev Argent Cardiol. 2011;79:125-31.

7. Turner I, Turek J, Jaggers J, Herlong R, Lawson D, Lodge A. Anomalous aortic origin of a coronary artery: preoperative diagnosis and surgical planning. World $J$ Pediatr Congenit Heart Surg. 2011;2:340-5.

8. Mumtaz M, Lorber R, Arruda J, Pettersson G, Mavroudis C. Surgery for anomalous aortic origin of the coronary artery. Ann Thorac Surg. 2011;91: $811-5$. 


\section{CLASS (STRENGTH) OF RECOMMENDATION}

\begin{tabular}{l} 
CLASS I (STRONG) \\
\hline Suggested phrases for writing recommendations: \\
- Is recommended \\
- Is indicated/useful/effective/beneficial \\
- Should be performed/administered/other \\
- Comparative-Effectiveness Phrasest: \\
- Treatment/strategy A is recommended/indicated in \\
- preference to treatment B \\
- Treatment A should be chosen over treatment B
\end{tabular}

CLASS Ila (MODERAIIE)
Suggested phrases for writing recommendations:
- Is reasonable
- Can be useful/effective/beneficial
- Comparative-Effectiveness Phrasest:
- Treatment/strategy A is probably recommended/indicated in
preference to treatment B
o It is reasonable to choose treatment A
over treatment B

CLASS Ilb (WEAK)
Suggested phrases for writing recommendations:
- May/might be reasonable
- May/might be considered
- Usefulness/effectiveness is unknown/unclear/uncertain
or not well established

\begin{tabular}{|c|c|}
\hline $\begin{array}{l}\text { CLASS III: No Benefit（MODERATE) } \\
\text { (Generally, LOE A or B use only) }\end{array}$ & Benefit = Risk \\
\hline $\begin{array}{l}\text { Suggested phrases for writing recommendations: } \\
\text { - Is not recommended } \\
\text { - Is not indicated/useful/effective/beneficial } \\
\text { - Should not be performed/administered/other }\end{array}$ & \\
\hline
\end{tabular}

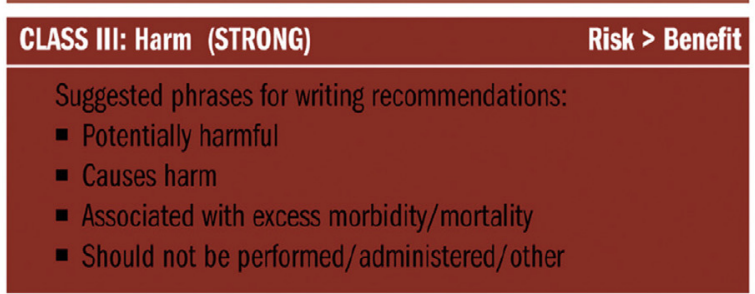

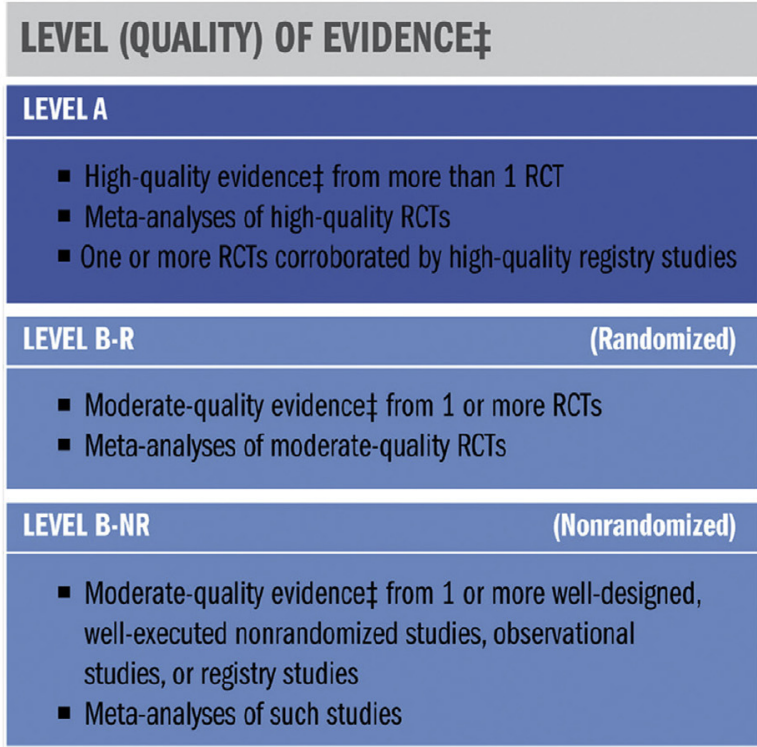

\section{LEVEL C-LD}

(Limited Data)

- Randomized or nonrandomized observational or registry studies with limitations of design or execution

- Meta-analyses of such studies

- Physiological or mechanistic studies in human subjects

\section{LEVEL C-EO}

(Expert Opinion)

Consensus of expert opinion based on clinical experience

COR and LOE are determined independently (any COR may be paired with any LOE).

A recommendation with LOE $C$ does not imply that the recommendation is weak. Many important clinical questions addressed in guidelines do not lend themselves to clinical trials. Although RCTs are unavailable, there may be a very clear clinical consensus that a particular test or therapy is useful or effective.

* The outcome or result of the intervention should be specified (an improved clinical outcome or increased diagnostic accuracy or incremental prognostic information).

† For comparative-effectiveness recommendations (COR I and Ila; LOE A and B only), studies that support the use of comparator verbs should involve direct comparisons of the treatments or strategies being evaluated.

¥ The method of assessing quality is evolving, including the application of standardized, widely used, and preferably validated evidence grading tools; and for systematic reviews, the incorporation of an Evidence Review Committee.

COR indicates Class of Recommendation; EO, expert opinion; LD, limited data; LOE, Level of Evidence; NR, nonrandomized; R, randomized; and RCT, randomized controlled trial.

FIGURE 2. American College of Cardiology/American Heart Association revised 2016 recommendation scheme for clinical practice guidelines. Reprinted with permission. ${ }^{16}$

9. Frommelt P, Sheridan D, Berger S, Frommelt M, Tweddell J. Ten-year experience with surgical unroofing of anomalous aortic origin of a coronary artery from the opposite sinus with an interarterial course. J Thorac Cardiovasc Surg. 2011;142:1046-51.

10. Sharma V, Burkhart H, Dearani J, Suri R, Daly R, Park S, et al. Surgical unroofing of anomalous aortic origin of a coronary artery: a single-center experience. Ann Thorac Surg. 2014;98:941-5.

11. Davis J, McBride M, Seliem M, Marino B, Tomlinson R, Pampaloni M, et al. Evaluation of myocardial ischemia following surgical repair of anomalous aortic origin of a coronary artery in a series of pediatric patients. J Am Coll Cardiol. 2007;50:2078-82.

12. Feins E, DeFaria Y, Bhatt A, Stefanescu A, Youniss M, Ghoshhajra B, et al. Anomalous aortic origin of a coronary artery: surgical repair with anatomicand function-based follow-up. Ann Thorac Surg. 2016;101:169-75.

13. Mainwaring R, Murphy D, Rogers I, Chan F, Petrossian E, Palmon M, et al. Surgical repair of 115 patients with anomalous aortic origin of a coronary artery from a single institution. World J Pediatr Congenit Heart Surg. 2016;7: $353-9$. 
14. Nguyen AL, Haas F, Evens J, Breur JM. Sudden cardiac death after repair of anomalous origin of left coronary artery from right sinus of Valsalva with an interarterial course: case report and review of the literature. Neth Heart J. 2012;20:463-71.

15. Brothers J, Carter C, McBride M, Spray T, Paridon S. Anomalous left coronary artery origin from the opposite sinus of Valsalva: evidence of intermittent ischemia. J Thorac Cardiovasc Surg. 2010;140:e27-9.
16. Halperin J, Levine G, Al-Khatib S, Birtcher K, Bozkurt B, Brindis R, et al. Further evolution of the ACC/AHA clinical practice guideline recommendation classification system. J Am Coll Cardiol. 2016;67: $1572-4$.

17. Housman AE. To an athlete dying young (1896). In: A Shropshire lad: authorized edition. London: Henry Holt \& Company; 1924. 